\title{
Analyzing the Effect of Using Axial Impellers in Large-Scale Bioreactors
}

\author{
Sören Bernauer ${ }^{1}$, Philipp Eibl ${ }^{2}$, Christian Witz ${ }^{2}$, Johannes Khinast ${ }^{2}$, and Timo Hardiman ${ }^{1}$ \\ ${ }^{1} \mathrm{Sandoz} \mathrm{GmbH}$ \\ ${ }^{2}$ Technische Universitat Graz
}

February 26, 2022

\begin{abstract}
In high-performance industrial fermentation processes, stirring and aeration may account for significant production costs. Compared to the widely applied Rushton impellers, axial-pumping impellers are known to yield a lower power draw and at the same time improve mixing. However, their lower gas dispersion capability requires stronger agitation, compromising these benefits. Diverse advanced impeller forms have been developed to cope with this challenge. We apply alternating radial and axial impellers and demonstrate strong gas dispersion and energy-efficient mixing for the first time in a large-scale $\left(160 \mathrm{~m}{ }^{3}\right.$ ) bioreactor, based on experimental and CFD simulation data. For equal operating conditions (stirrer speed, aeration rate), this setup yielded similar gas hold-ups and better mixing times (-35\%) compared to a classical Rushton-only configuration. Hence, applying a radial impeller on an upper level for improving gas dispersion maintains the benefits of axial impellers in terms of reducing energy demand (up to $-50 \%$ ). We conclude that this effect is significant only at large-scale, when bubbles substantially expand due to the release of the hydrostatic pressure and have time to coalesce. The work thus extends current knowledge on mixing and aeration of large-scale reactors using classical impeller types.
\end{abstract}

\section{Hosted file}

Main Document.docx available at https://authorea.com/users/337675/articles/557914-analyzingthe-effect-of-using-axial-impellers-in-large-scale-bioreactors 